\title{
Nondestructive Characterization of Voids in Rear Local Contacts of PERC-Type Solar Cells
}

\author{
Katharina Dressler, Miriam Rauer, M. Kaloudis, Stefan Dauwe, Axel Herguth, and Giso Hahn
}

\begin{abstract}
In this paper, we present two nondestructive characterization methods for the detection of voids in rear local contacts of passivated emitter and rear-type solar cells, namely scanning acoustic microscopy and computer tomography. We compare both methods and include a comparison with electroluminescence measurements. It is shown in this paper that voids can easily be detected with both measurement types without any sample preparation. We found a good match of scanning acoustic microscopy (SAM) and computer tomography (CT), which is presented for this purpose for the first time. The investigation was carried out for different aluminum pastes.
\end{abstract}

Index Terms-Computer tomography (CT), crystalline silicon, passivated emitter and rear cell concept (PERC), scanning acoustic microscopy (SAM), solar cells, voids.

\section{INTRODUCTION}

$\mathbf{T}$ HE PASSIVATED emitter and rear cell concept (PERC), first proposed by Blakers et al. [1], becomes more and more important for the standard crystalline silicon ( $\mathrm{Si}$ ) solar cell production. By adding only a few process steps, cell efficiencies more than $21 \%$ on large-area $\left(15.6 \times 15.6 \mathrm{~cm}^{2}\right)$ Czochralski $(\mathrm{Cz})$ monocrystalline Si solar cells have been reached [2], [3]. A well-known problem of the PERC concept is the formation of voids in the rear local contacts [4], [5]. The Kirkendall effect [6] is a good explanation for the void formation, as Si diffuses much faster in $\mathrm{Al}$ than $\mathrm{Al}$ in $\mathrm{Si}$ [4].

The most commonly used characterization methods for void detection and investigation are optical and electron microscopy of cross sections as well as electroluminescence (EL) measurements. However, there are a few drawbacks: The preparation of a cross section is a destructive method, and therefore, a further processing into solar modules is not possible. Furthermore, the information about the appearance of voids is locally restricted, while voids in line-shaped local contacts may stretch about several centimeters. EL measurements are nondestructive, but only voids without a local back surface field (BSF) can be detected,

K. Dressler, A. Herguth, and G. Hahn are with the University of Konstanz, 78457 Konstanz, Germany (e-mail: katharina.dressler@uni-konstanz.de; axel.herguth@uni-konstanz.de; giso.hahn@uni-konstanz.de).

M. Rauer and M. Kaloudis are with the University of Applied Sciences Aschaffenburg, 63743 Aschaffenburg, Germany (e-mail: miriam.rauer@h-ab.de; michael.kaloudis@h-ab.de).

S. Dauwe is with the h.a.1.m. electronik GmbH, 60389 Frankfurt am Main, Germany (e-mail: s.dauwe@halm.de). as EL is sensitive to recombination, which in turn lowers locally the quasi-Fermi level splitting and carrier concentration, respectively. In reality, often a local BSF is still present after void formation which cannot be detected by EL. Voids with a local $\mathrm{BSF}$ connected to the rear contact do not have a direct impact on cell efficiency, but the cavities between $\mathrm{Si}$ and metallization may deteriorate the adhesion which can cause problems in solar modules. This is one reason why characterization methods for void detection are important for the production of PERC-type solar cells.

A very good nondestructive characterization method for void detection is scanning acoustic microscopy (SAM) [7]. In this study, we introduce computer tomography (CT) as another nondestructive characterization method and compare it with SAM measurements.

\section{EXPERIMENTAL DETAILS}

Characterization is carried out on $15.6 \times 15.6 \mathrm{~cm}^{2}$ monocrystalline (mono) $\mathrm{Cz}$ Si wafers, with an as-cut wafer thickness of 180-200 $\mu \mathrm{m}$. The solar cells were alkaline textured and have a homogeneous $60 \Omega / \square$ phosphorous emitter formed by a $\mathrm{POCl}_{3}$ based tube furnace diffusion step. After diffusion, the emitter on the rear side has been removed in a wet-chemical edge isolation step. On the front side, the emitter is covered with a plasmaenhanced chemical vapor deposition (PECVD) silicon nitride antireflective coating and a standard screen printed Ag frontside grid. On the rear surface, a standard dielectric passivation stack, consisting of a thin aluminum oxide layer capped with a silicon nitride layer, was deposited in a PECVD system. The line-shaped contact openings on the rear side were formed by laser ablation [8]. For simplification of characterization, laser openings were made perpendicular to the front-side fingers. The rear side was metallized with two different $\mathrm{Al}$ screen printing pastes covering the full area. Paste 1 is a commercially available $\mathrm{Al}$ paste for PERC cells, and paste 2 a homemade $\mathrm{Al}$ paste, also for PERC cells. The cells have been fired at temperature profiles optimized for cofiring processes.

To get information about high rear local contact resistivities, the cells were measured with EL (see Figs. 1 and 2). Dark areas in EL images, measured at $10 \mathrm{~A}$ cell current, show regions with poor electrical contact. From former investigations, it is known that these regions with high rear local resistivities can be attributed to the occurrence of voids [7]. Afterward, SAM and CT measurements were carried out on the whole solar cells, respectively, on a $15.6 \times 12.0 \mathrm{~cm}^{2}$ area, because of geometrical restrictions in the measurement chamber (see white marker in Figs. 1 and 2), and, for a better comparability, on $2 \times 2 \mathrm{~cm}^{2}$ areas (see red marker in Figs. 1 and 2). 


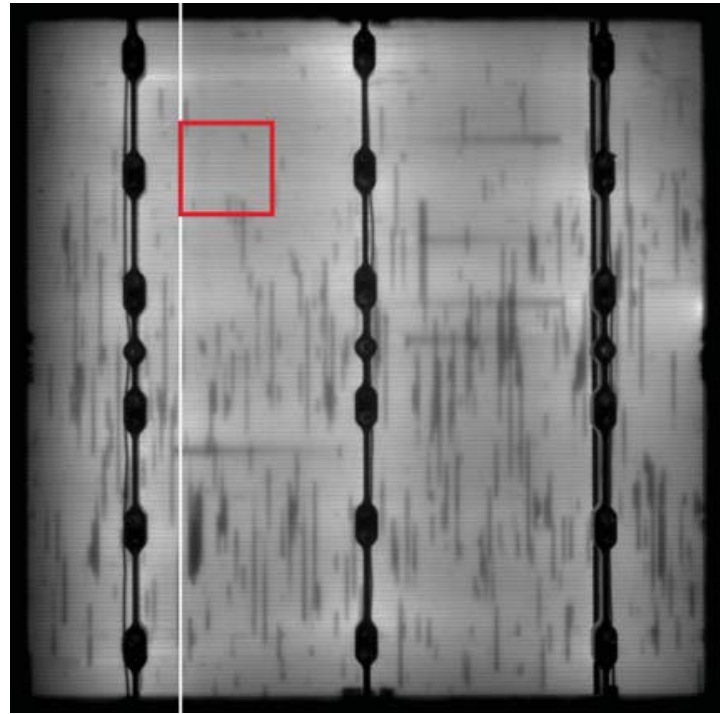

Fig. 1. EL measurement at 10 A of a mono Si $15.6 \times 15.6 \mathrm{~cm}^{2}$ PERC cell, metallized with paste 1 . Red marker: position for $2 \times 2 \mathrm{~cm}^{2} \mathrm{SAM}$ and CT measurements. White marker: position of the cut for the CT measurement. The three extended dark areas lying vertically along the busbars are artifacts due to the contacting setup.

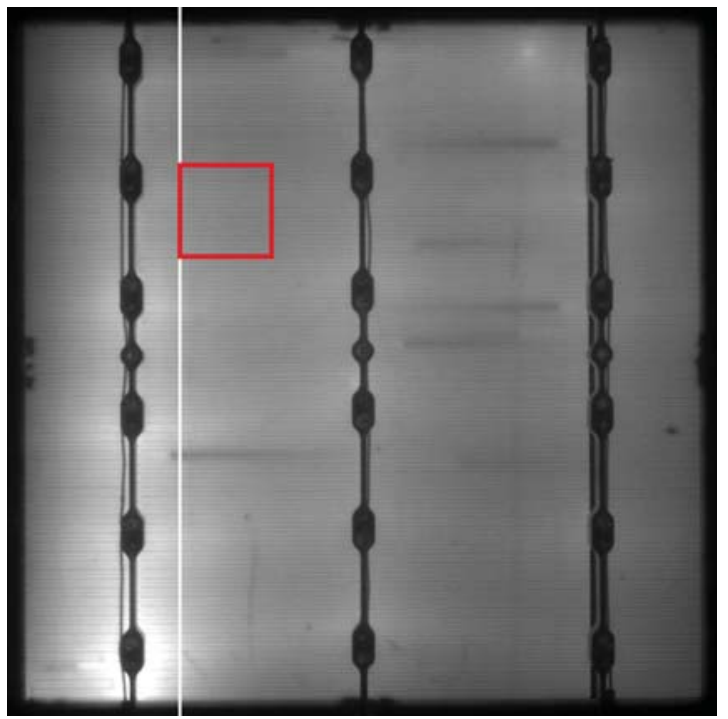

Fig. 2. EL measurement at $10 \mathrm{~A}$ of a mono Si $15.6 \times 15.6 \mathrm{~cm}^{2}$ PERC cell, metallized with paste 2 . Red marker: position for $2 \times 2 \mathrm{~cm}^{2} \mathrm{SAM}$ and CT measurements. White marker: cut for the CT measurement.

\section{A. Scanning Acoustic Microscopy}

With a scanning acoustic microscope, voids in rear local contacts of PERC-type solar cells can be detected without any sample preparation. A schematic of the functional principle is shown in Fig. 3. For this experiment, a V400 system from Kramer Sonic Industries was used. The solar cell is fixed, the $\mathrm{Al}$ rear side facing upward, on a magnetic sample stage by small stripes or wires made from a ferromagnetic material. These stripes help to keep the sample very flat on the sample stage and prevent sample floating during measurement. In the resulting measurement images, one can see the fixing stripes as dark measurement arte-

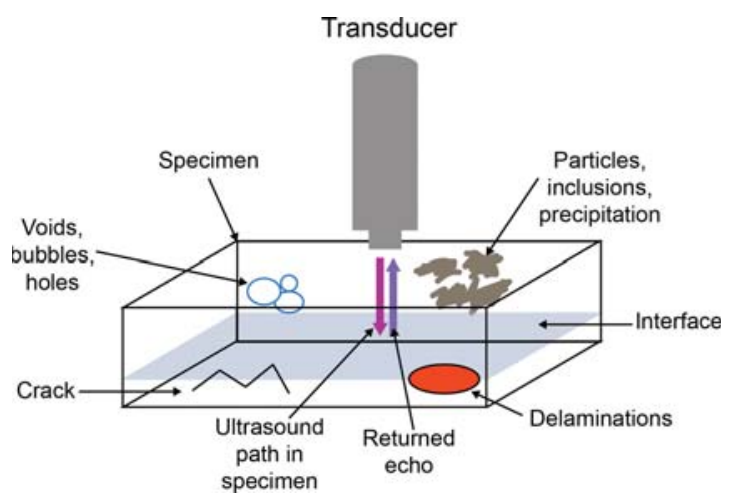

Fig. 3. Schematic of the functional principle of the scanning acoustic microscope (according to [8]).

facts. The sample stage is submerged in deionized water, which helps to transmit the signal to the sample as the reflection at the interface air/Al or air/Si would be extremely strong ( $>99 \%)$. An ultrasonic signal is generated and focused on the sample by a transducer. Due to the interaction of the signal with the scanned material, a part of the signal is reflected back to the transducer as an echo. The transition from water to $\mathrm{Al}$ or $\mathrm{Si}$ (or the other way around) yields a strong reflection of around $70 \%$, while the reflection at the $\mathrm{Al} / \mathrm{Si}$ interface is weak $(<1 \%)$. If the sound waves hit an air- or water-filled pocket, strong reflection or scattering occurs, and the transmitted signal is weak. In consequence, the reflected/scattered signal from an object/interface under investigation beyond the pocket is weak (even though the reflection would be strong) and, thus, appears dark in the measured image.

For the analysis of the echo, the amplitude, the phasing, and the runtime are used to generate a gray-shaded image. Commonly, the signal is evaluated over a period of time with a certain delay relative to the first echo reflected at the water/sample interface as the voids investigated here are lying below the surface. If the delay is chosen appropriately, the transducer mainly registers signals from the $\mathrm{Al} / \mathrm{Si}$ interface or beyond, and air/water-filled voids will show up as areas with weak signal intensity, as the main part of the intensity already got lost within the delay. As the Al thickness and the void depth may differ from sample to sample, it has proven viable to simply take a series of images with different delays (and thus depth) and selecting the best image afterward.

The solar cell is scanned line by line; therefore, the measurement time depends on the sample size and typically takes seconds to several minutes. For the horizontal resolution, the used setup allows us to choose the number of pixels between $125,250,500$, and 1000. The vertical resolution can be chosen between the same as for horizontal resolution, one half, one quarter, etc., up to $1 / 16$. The penetration depth depends on the frequency and the focal length of the transducer. The used transducer has a frequency of $150 \mathrm{MHz}$ and a focal length of $2 \mathrm{~mm}$; therefore, it can be used for thin samples [9].

\section{B. Computer Tomography}

$\mathrm{CT}$ is a nondestructive test method which can be used for the analysis of inner structures and the detection of extended 


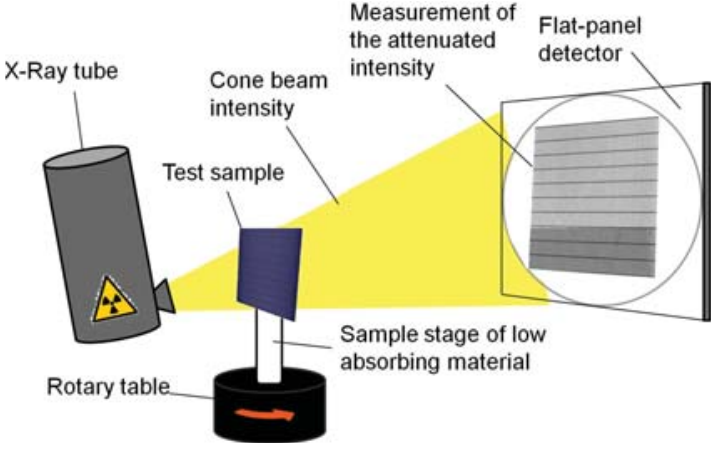

Fig. 4. Schematic of the functional principle of CT.

defects like voids. The principle of CT is shown in Fig. 4. The sample stage has to ensure that the specimen does not move during measurement. Normally, it consists of a lower absorbing material compared with the specimen so that it can easily be blanked out during the interpretation. The X-radiation, in form of a cone beam, penetrates the object and is partially absorbed by the sample. During the measurement, the test object rotates by $360^{\circ}$ while the detector captures a series of 2-D projected images. A 3-D dataset of volume elements (voxels) is reconstructed based on appropriate algorithms and high-performance computers [10].

Once the dataset has been reconstructed, the test object can be illustrated and analyzed for defects with the help of the software application VG Studio MAX 2.1 by Volume Graphics GmbH, Heidelberg, Germany. The application software visualizes the volume model of the test object, as well as three different CT cutting planes through the volume model of the test object at the same time. The CT cutting planes are freely selectable planes, and thus, each layer and the inner structures of the reconstructed test object can be analyzed.

The different grayscale values in the reconstructed dataset result from different attenuation levels of the radiation as a function of the atomic number and the thickness of the irradiated material [11]. In the CT cutting planes, low absorbing materials appear darker, while high absorbing materials appear brighter. In contrast, the classification of the gray values in the volume model is different. In this case, the low absorbing materials show a brighter contrast than the high absorbing materials.

The used computer tomographs exaCT $® S$ and exaCT $® M$ by Wenzel Volumetrik have a maximum voxel resolution of 5 and $42 \mu \mathrm{m}$, respectively, and thus belong to the class of microcomputer tomographs. However, the maximum resolution of the computer tomograph exaCTßS can only be achieved by positioning the measured object directly in front of the X-ray tube. The conical shape of the beam results in a magnification of the irradiated object on the detector. This way, the sample is represented on the detector with more detector pixels. With smaller samples, a higher resolution, compared with larger samples, can be achieved because of the closer positioning to the $\mathrm{X}$-ray source [12], whereas the computer tomograph exaCT $® \mathrm{M}$ has a fixed position in front of the detector.

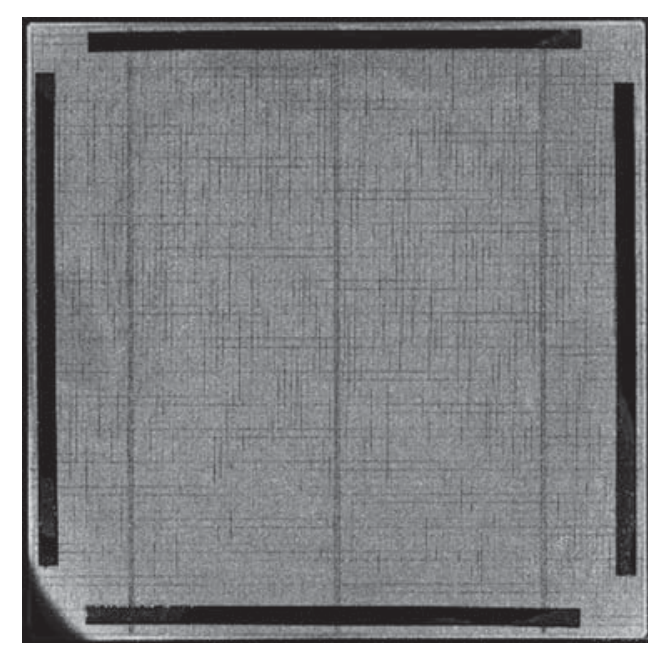

Fig. 5. SAM measurement of a $15.6 \times 15.6 \mathrm{~cm}^{2} \mathrm{Cz}$ PERC-type solar cell metallized with paste 1 . The dark area along the edges are artifacts due to the sample mounting.

\section{RESULTS}

For a first analysis of the solar cells under investigation, EL measurements have been carried out. When a paste tends to form a lot of voids within the firing process, there is a good chance that there are voids without a local BSF in the contact opening. Alternatively, the conductivity of the remaining material is not high enough to support the current flow through the rear contact, e.g., when the local BSF shows poor contact to the rear $\mathrm{Al}$ layer. In both scenarios, voids that are detrimental for the solar cell can be detected with EL measurements. Figs. 1 and 2 show EL images of PERC-type Cz-Si solar cells, measured at $10 \mathrm{~A}$ cell current. The used Al pastes differ in void formation, although for both pastes optimal firing conditions have been applied. For paste 1, the results of the SAM measurements have already been proven in former investigations (referred to as "paste 2" in [7]).

The EL measurement of the cell metallized with paste 1 (see Fig. 1) confirms the high amount of voids in the rear local contacts. The vertical thin dark lines show the voids without a local BSF. The horizontal lines result from finger interruptions on the front side of the solar cell. The second paste used for this experiment only forms few voids. The reason for a reduced void formation is still under investigation and is not important for the evaluation of the presented characterization techniques. The corresponding EL measurement is shown in Fig. 2. As there is no extensive void formation occurring when using this paste, also no high rear local contact resistivities are expected. The corresponding EL image confirms this assumption.

\section{A. Comparison of Scanning Acoustic Microscopy With Computer Tomography Measurements}

For comparison of these two nondestructive techniques, the same solar cells were measured with SAM and CT, and the resulting images of the cell metallized with paste 1 are shown in Figs. 5 and 6, respectively. 


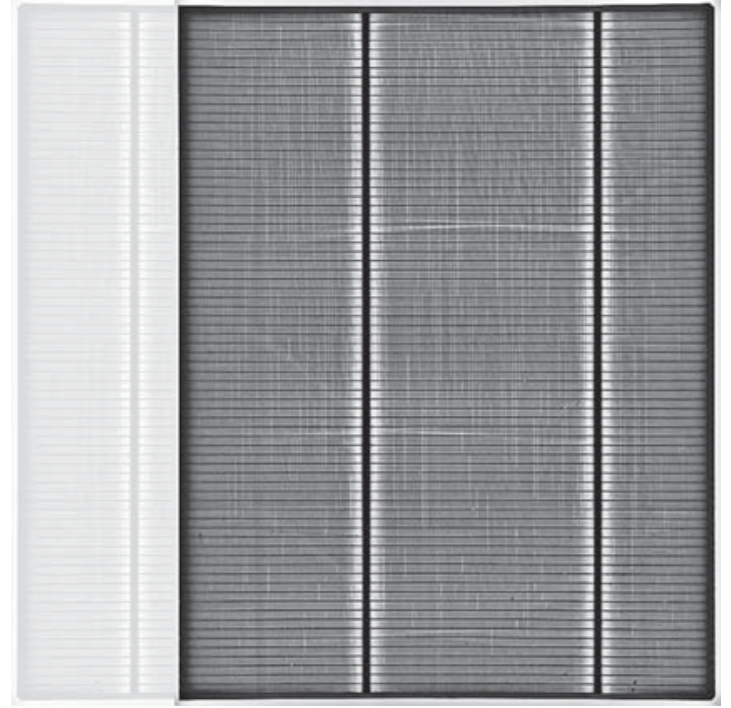

Fig. 6. CT measurement of the $15.6 \times 12.0 \mathrm{~cm}^{2}$ detail of the solar cell metallized with paste 1 .

In the SAM image, one can see the Ag front-side grid with three vertical busbars and perpendicular fingers as dark lines. The line-shaped rear contacts run parallel to the busbars in vertical direction. The four dark areas on the borders of the solar cell are artefacts due the mounting of the cell on the sample stage (see Section II-A). The dark area in the lower left corner is a measurement artefact caused by the cell bow. The four mounting stripes are not long enough to fix the corners flat on the sample stage. The resolution for this SAM measurement is $156 \mu \mathrm{m}$ in each direction. As expected, there are a lot of voids visible in the rear local contacts.

Due to the limitation of the sample chamber of the exaCTßM and the required rotation during the measurement, the sample may have a maximum width of $12 \mathrm{~cm}$; therefore, on the left side, a stripe had been cut off (see white marker in Fig. 1). The resulting CT measurement shows the volume model in Fig. 6. As discussed in Section II-B, low absorbing materials appear brighter than higher absorbing materials in the volume model. This behavior is contrary to the gray values in CT cutting planes. Therefore, the Ag front-side grid can be seen as dark lines. In the volume model, the voids in the rear local contacts are the vertical bright lines, the front fingers are the horizontal dark ones, whereas in the CT cutting plane parallel to the sample surface, the voids appear dark, and the Ag front fingers appear bright. The CT measurement also detects a lot of voids.

For a better comparability of void detection, $2 \times 2 \mathrm{~cm}^{2}$ details of the solar cells were cut out and measured (see red markers in Figs. 1 and 2). In Fig. 7(a), a SAM image of the solar cell metallized with paste 1 (compare Fig. 1) is shown. The vertical dark lines show the unfilled regions in the rear local contacts. The dark areas on the upper left and the lower right corner are due to the mounting of the sample. Fig. 7(b) shows the corresponding $\mathrm{CT}$ image. The horizontal lines are the Ag front fingers and the dark vertical ones correspond to the voids. Investigating these two images closer, starting at the left side, one can observe in

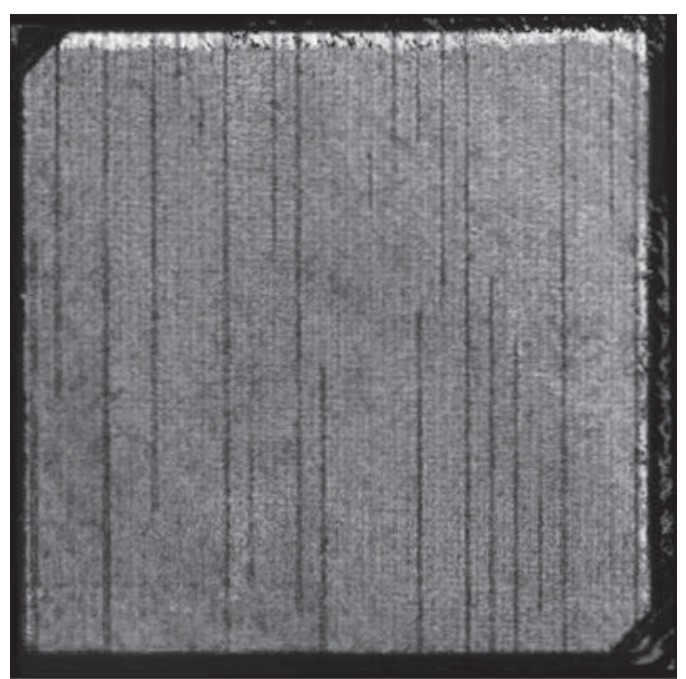

(a)

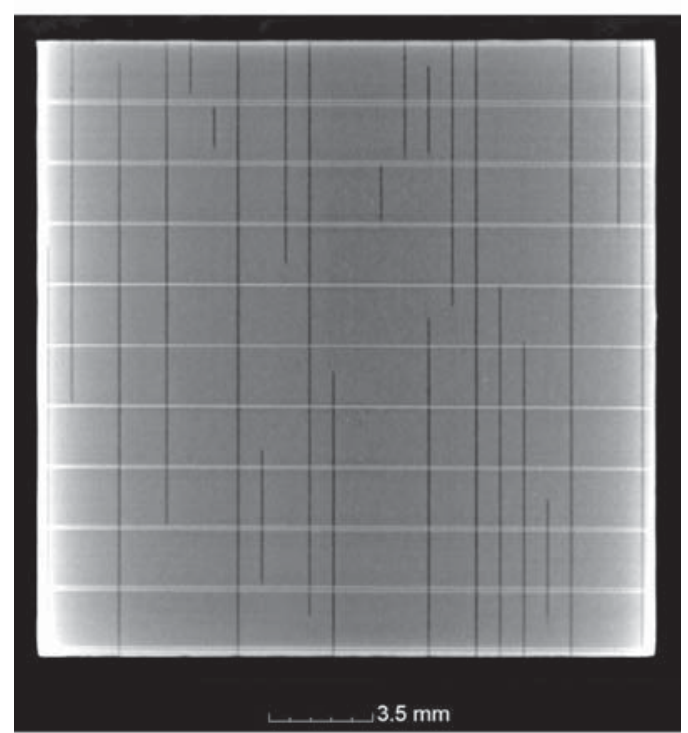

(b)

Fig. 7. (a) SAM image of the $2 \times 2 \mathrm{~cm}^{2}$ area of the PERC-type solar cell metallized with paste 1. (b) CT image of the same cell area (white horizontal lines are correlated to the front-side Ag fingers).

both images a void running from the upper edge to the center of the image, followed to the right by a void that stretches about the entire height. After another void, approximately $75 \%$ of the whole contact length, there are two short ones visible in both images. One can see that the two measurement images clearly show identical void formation.

Fig. 8(a) and (b) shows SAM and CT measurements from the detail of the PERC-type solar cell metallized with paste 2 (compare Fig. 2). As before, the front fingers run horizontally through the sample, the local contacts perpendicularly to them. There are only a few voids expected on solar cells metallized with this paste, and indeed, the CT measurement shows only few very small but well-identifiable voids. For a better perceptibility, they are dyed in red. In the corresponding SAM image, there are several dark round areas. These dark areas can be voids or they can be caused by small particles on the cell rear surface 


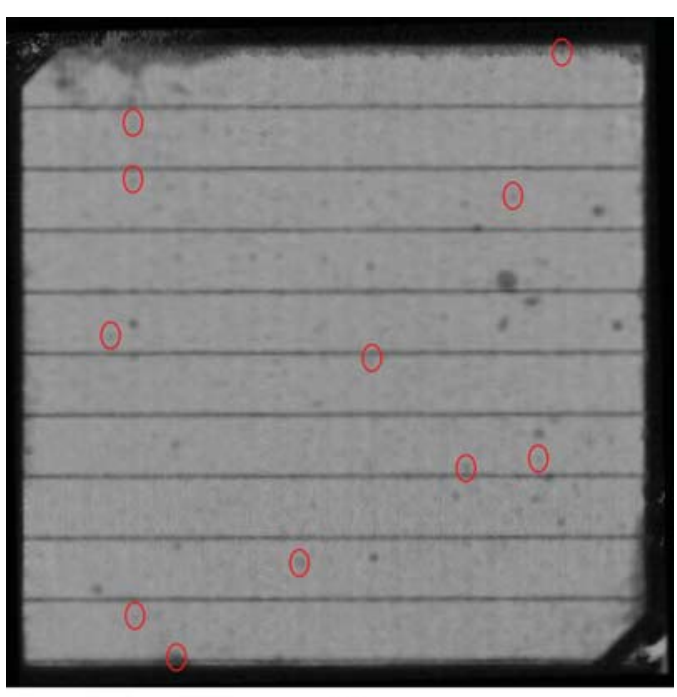

(a)

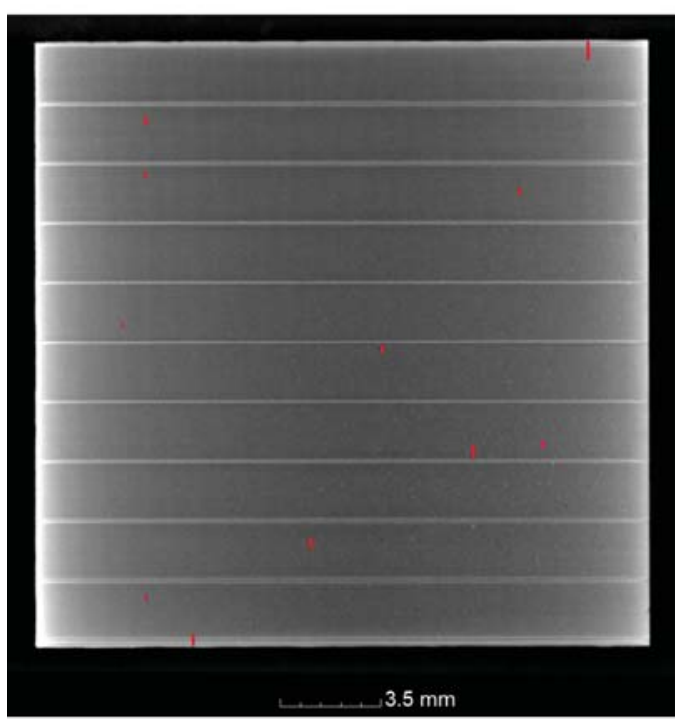

(b)

Fig. 8. (a) SAM image of the $2 \times 2 \mathrm{~cm}^{2}$ area of the PERC-type solar cell metallized with paste 2. (b) CT image of the same cell area.

which cannot be removed. Compared with the corresponding CT image, there are small dark areas observable at the positions of the voids detected with CT. SAM and CT images of a complete cell metallized with paste 2 are not shown in this paper. As for this paste only a few small voids are expected, it is not easy to visualize them on the scan of the complete large-area solar cell.

\section{DISCUSSION}

To get a good SAM image, it is necessary to ensure that the sample is fixed lying flat on the planar sample stage. Only small height differences can cause measurement artefacts, like in the lower left corner of Fig. 5. Depending on the cell bow, the stripes to fix the sample can differ in width, but they are usually not broader than in Fig. 5.

For a complete SAM measurement of a $15.6 \times 15.6 \mathrm{~cm}^{2}$ solar cell, a resolution of $156 \mu \mathrm{m}$ was found to be appropriate for void detection with acceptable measurement time. The measurement software integrates "on the fly" over these $156 \mu \mathrm{m}$ in the measurement direction, and as long as the width of the void or the amplitude change of the signal is large enough, the void can be detected. As the voids in rear local contacts investigated here have a typical width of $50-80 \mu \mathrm{m}$ and a typical depth of $10-20 \mu \mathrm{m}$, the resolution is high enough to get reliable results. Of course, there can be problems, if the local contacts are not completely unfilled. Perpendicular to the scan direction, the resolution was also chosen to be $156 \mu \mathrm{m}$. However, the transducer features principally a focus diameter between 20 and $30 \mu \mathrm{m}$, which is smaller than $156 \mu \mathrm{m}$, and the scanned lines do not overlap. The system is virtually blind in the areas not covered by the scan, and voids might not be detected within these blind regions. Therefore, it is recommended to scan perpendicularly to the void lines for a reliable void detection. The measurement time for a whole cell with this resolution is about $15 \mathrm{~min}$. The $2 \times 2 \mathrm{~cm}^{2}$ details are measured with a resolution of $20 \mu \mathrm{m}$. With this resolution, the measurement also takes about $15 \mathrm{~min}$. This resolution had been chosen to get very clear images. Of course, the larger voids could also be detected with a lower resolution, and therefore, the measurement time could be shorter.

With a SAM measurement of small samples with only small voids and a rough rear surface, e.g., metalized with paste 2 , no clear results can be achieved. In the SAM image, the particles on the cell surface and the small voids in the local contacts (red circles in Fig. 8(a)) cannot be distinguished from each other. However, for the performance of the complete solar cell, this low amount of small structures does not seem to be a problem anyway, as fill factors are not negatively affected. If there are only few very small voids present, the adhesion between paste and silicon might not be significantly degraded.

In addition, for the $\mathrm{CT}$ measurement, the cell bow causes problems. Because of the bow, it is hardly possible to get an image of the cutting plane of the whole cell as it is possible for the smaller $2 \times 2 \mathrm{~cm}^{2}$ areas (see Figs. 7 and 8). This is the case in Fig. 6 in which the volume model instead of the cutting plane is depicted.

In the $\mathrm{CT}$ measurement of the $15.6 \times 12.0 \mathrm{~cm}^{2}$ detail of the solar cell, a resolution of $84 \mu \mathrm{m}$ is reached. A measurement of that area with this resolution takes $\sim 6 \mathrm{~h}$ because the $15.6 \times 12.0 \mathrm{~cm}^{2}$ area is divided into five areas which are measured consecutively and assembled by the software afterward. For a good detection of details on the $2 \times 2 \mathrm{~cm}^{2}$ parts of the solar cells, a resolution of $25 \mu \mathrm{m}$ was chosen on the computer tomograph exaCT $\circledast \mathrm{S}$ and measurement time was $\sim 45$ min.

For defect analysis by means of CT, it is important that there is enough contrast between the void (mostly filled with a low absorbing material like air or gas) and the surrounding materials. Other factors to be considered for a clear analysis of voids are an artefact-free measurement, the used voxel resolution, and the size of the defects. As can be seen in Fig. 6, the detection of voids in the solar cell is possible with no problems. 


\section{CONCLUSION}

In this study, CT was introduced as a nondestructive method for the detection of voids in rear local contacts of PERC-type solar cells. To confirm the results of CT measurements, $2 \times$ $2 \mathrm{~cm}^{2}$ details of solar cells were measured and compared with scanning acoustic microscope images of the same areas (see Figs. 7 and 8).

Compared with standard EL measurements, it could be shown that both CT and SAM are good alternatives for void characterization, and even voids with local BSF can be detected.

For the detection of voids with larger dimensions, both methods can reliably detect voids in a nondestructive way; however, measurement time with the SAM is considerably shorter, mainly for larger samples. For solar cells with a rough rear surface and very small voids, in our investigation, only CT measurements could reliably detect the voids.

\section{ACKNOWLEDGMENT}

K. Dressler would like to thank her former colleagues at SCHOTT Solar for the excellent collaboration. The content of this publication is the responsibility of the authors.

\section{REFERENCES}

[1] A. W. Blakers, A. Wang, A. M. Milne, J. Zhao, and M. A. Green, " $22.8 \%$ efficient solar cell," Appl. Phys. Lett., vol. 55, no. 13, pp. 1363-1365, Sep. 1989.

[2] A. Metz, D. Adler, S. Bagus, H. Blanke, M. Bothar, E. Brouwer, S. Dauwe, K. Dressler, R. Droessler, T. Droste, M. Fiedler, Y. Gassenbauer, T. Grahl, N. Hermert, W. Kuzminski, A. Lachowicz, T. Lauinger, N. Lenck, M. Manole, M. Martini, R. Messmer, C. Meyer, J. Moschner, K. Ramspeck, P. Roth, R. Schönfelder, B. Schum, J. Sticksel, K. Vaas, M. Volk, and K. Wangemann, "Industrial high performance crystalline silicon solar cells and modules based on rear surface passivation technology," Sol. Energy Mater. Sol. Cells, vol. 120, pp. 417-425, Jan. 2014.

[3] (Apr. 2014). 21.2\% world record efficiency for industrial PERC silicon solar cell, Institute for Solar Energy Research Hamelin, Emmerthal, Germany, Press release. [Online]. Available: http://www.isfh.de/institut_solarforschung/pressemitteilungen.php?mod $=$ ctext_show\&ctext_id $=2070 \& c l=1$ lang $\& \_1=1$

[4] E. Urrejola, K. Peter, H. Plagwitz, and G. Schubert, "Silicon diffusion in aluminum for rear passivated solar cells," Appl. Phys. Lett., vol. 98, p. 153508, Apr. 2011.

[5] T. Lauermann, A. Zuschlag, S. Scholz, G. Hahn, and B. Terheiden, "The influence of contact geometry and sub contact passivation on the performance of screen printed $\mathrm{Al}_{2} \mathrm{O}_{3}$ passivated solar cells," in Proc. 26th Eur. Photovoltaic Sol. Energy Conf., Hamburg, Germany, 2011, pp. 1137 1143.

[6] E. O. Kirkendall, "Diffusion of zinc in alpha brass," Trans. AIME, vol. 147, pp. 104-109, Feb. 1942

[7] K. Dressler, S. Dauwe, T. Droste, J. Rossa, B. Meidel, K. Schünemann, K. Rampsbeck, Y. Gassenbauer, and A. Metz, "Characterisation of rear local contacts including BSF formation using Raman and scanning acoustic microscopy," in Proc. Eur. Photovoltaic Sol. Energy Conf., Frankfurt, Germany, 2012, pp. 755-758.

[8] Y. Gassenbauer, K. Rampsbeck, B. Bethmann, K. Dressler, J. D. Moschner, M. Fiedler, E. Brouwer, R. Drößler, N. Lenck, M. Feldhaus, M. Müller, and A. Metz, "Rear surface passivation technology for crystalline silicon solar cells: A versatile process for mass production," IEEE J. Photovoltaics, vol. 3, no. 1, pp. 125-130, Jan. 2013.

[9] SAM Functional Principle (Scanning Acoustic Microscope). KSI Germany, Dorsten, Germany. (2014). [Online]. Available: http://www.ksigermany.de/acousticmicroscopy-de/technology-transducer.php

[10] P. O. Moore, Nondestructive Testing Handbook: Radiographic Testing, vol. 4, 3rd ed. Columbus, OH, USA: Amer. Soc. Nondestructive Testing, 2002.
[11] T. Buzug, "Fundamentals of X-ray physics," in Computed TomographyFrom Photon Statistics to Modern Cone-Beam CT. Berlin, Heidelberg: Springer, 2010, pp. 46-48.

[12] S. R. Stock, Micro-Computed Tomography_Methodology and Applications. Boca Raton, FL, USA: Taylor \& Francis, 2009.

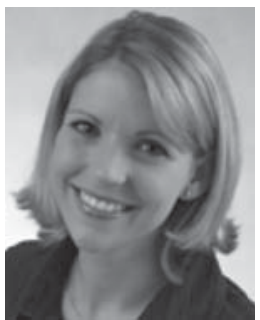

Katharina Dressler received the Diploma degree in electrical engineering from the University of Applied Sciences Aschaffenburg, Aschaffenburg, Germany, in 2009. She is currently working toward the Ph.D. degree in physics with the Technical University Bergakademie Freiberg, Freiberg, Germany.

From 2009 to 2012, she was a Development Engineer for the SCHOTT Solar AG in the metallization group. Her focus was the rear-side metallization of passivated emitter and rear cell concept (PERC)-type solar cells. Since 2013, she has been with the Photovoltaics division with the University of Konstanz, Konstanz, Germany, also on PERC metallization.

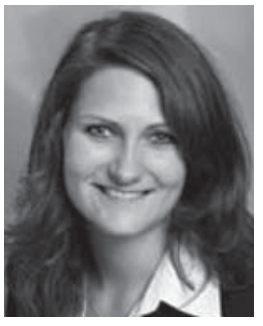

Miriam Rauer received the B.Eng. degree in industrial engineering in 2010 and the M.Eng. degree in electrical engineering and information technology in 2012, both from the University of Applied Sciences Aschaffenburg, Aschaffenburg, Germany. She is currently working toward the Dr.Ing. degree in mechanical engineering with Friedrich-Alexander-University Erlangen-Nuremberg, Erlangen, Germany.

Since 2010, she has been a Research Assistant with the Packaging and Interconnection Laboratory, University of Applied Science Aschaffenburg. Her research interest includes the investigation of microelectronic assemblies using $\mathrm{X}$-ray computer tomography. In this context, particular attention is in the field of voids in solder joints and their influence on the reliability.

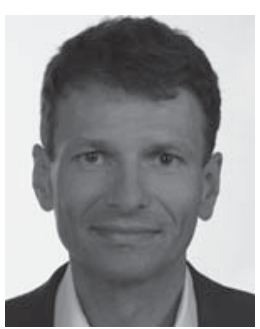

M. Kaloudis received the Diploma degree in physics from the University of Munich, Munich, Germany, in 1992 and the Ph.D. degree in physics from the University of Göttingen, Göttingen, Germany, in 1996.

He was with Max-Planck-Institute for Flow Research, Göttingen, from 1992 to 1996 and with Blaupunkt Werke GmbH, Hildesheim, Germany, from 1996 to 1999. Since 1999, he has been a Professor with the Faculty of Engineering, University of Applied Sciences Aschaffenburg, where he is the Head of the Packaging and Interconnection Laboratory. Since 2013, he has been the Dean of the Faculty of Engineering.

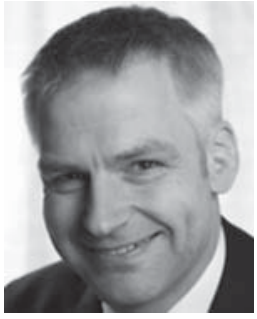

Stefan Dauwe received the Ph.D. degree in physics from the University of Hanover, Hanover, Germany, in 2003.

$\mathrm{He}$ is currently with h.a.l.m. elektronik $\mathrm{GmbH}$, Frankfurt, Germany. He was employed by SCHOTT Solar AG, Alzenau, Germany, from 2006 to 2012, where he was the Head of the Metallization group of the $R \& D$ department. R\&D activities of this group included development and optimization of materials and processes for the front as well as rear-side metallization of crystalline silicon solar cells. 


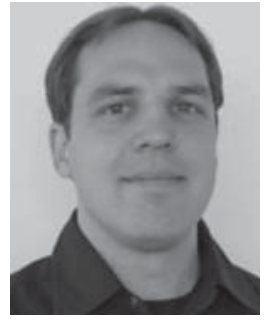

Axel Herguth received the Diploma degree in physics from the University of Konstanz, Konstanz, Germany, in 2006.

Since 2007, he has been the Head of the characterization group in the Photovoltaics Division, University of Konstanz. His research interests include the kinetics of defects in silicon in general, especially the kinetic of the metastable boron-oxygen-related defect, as well as characterization techniques for silicon wafers and solar cells.

Mr. Herguth received the Junior Einstein Award from Solarworld in 2006 for his work on the avoidance of the boron-oxygenrelated degradation.

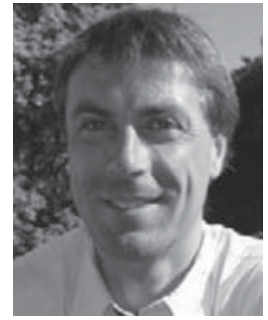

Giso Hahn received the Ph.D. degree in physics from the University of Konstanz, Konstanz, Germany, in 1999.

Since 2009, he has been a Professor with the Department of Physics, University of Konstanz, where he is the Head of the Photovoltaics Division, which is focused on crystalline silicon materials and solar cell process development. His research interests include the characterization of promising low-cost materials for photovoltaic applications and the development materials.

Dr. Hahn is a member of the scientific committees of various conference series and workshops. Among other scientific and technological achievements, his group is interested in transferring technologies from the laboratory stage to industry. 